\title{
A survey of the training of traditional, complementary, and alternative medicine in universities in Thailand
}

This article was published in the following Dove Medical Press journal: Journal of Multidisciplinary Healthcare

\author{
Karl Peltzer ${ }^{1,2}$ \\ Supa Pengpid ${ }^{2,3}$ \\ 'HIVIAIDS/STIs and TB Research \\ Programme, Human Sciences \\ Research Council, Pretoria, South \\ Africa; ${ }^{2}$ Department of Research and \\ Innovation, University of Limpopo, \\ Turfloop, South Africa; ${ }^{3}$ ASEAN \\ Institute for Health Development, \\ Mahidol University, Salaya, \\ Phutthamonthon, Nakhon Pathom, \\ Thailand
}

Background: Traditional, complementary, and alternative medicine (TCAM) is popularly used by the Thai population. The aim of this study was to determine whether undergraduate medical curricula included TCAM and, if so, to ascertain what kind of education was provided. In addition, where undergraduate degrees in TCAM were offered, the type of TCAM curricula, research, training, and collaboration were examined.

Methods: In a cross-sectional survey, academic or curriculum deans and faculty at each of the medical schools (response rate $76.2 \%$ of 21 ) and each of the TCAM faculties and departments (response rate $77.8 \%$ of 18 ) in Thailand responded to a questionnaire on characteristics of their TCAM curriculum.

Results: Half of the medical schools (50\%) confirmed the presence of TCAM education in their medical school, of which most were a required and some an elective course. In all surveyed 14 TCAM departments or faculties a bachelor's degree and in five institutions a master's degree in TCAM are offered. Undergraduate and postgraduate degrees include Thai Traditional Medicine, Applied Thai Traditional Medicine, Chinese Traditional Medicine, and Oriental Medicine. All the programs offered a research course and almost all indicated that their curriculum covers "scientific proofs about the efficacy and safety of treatments." More than half (9) indicated that their curriculum covers "how TCAM professionals should interact with biomedical peers in their practice."

Conclusion: Regarding TCAM training modules of medical undergraduates, only $50 \%$ of medical schools had integrated TCAM training in their curriculum. It will be important to give all medical students exposure to TCAM practices in their curriculum. Regarding the implementation of TCAM bachelor's degrees, the study confirmed the importance of the integration of research methodology, evidence-based health care, and interprofessional communication into the training of TCAM providers' training and practice.

Keywords: Thai traditional medicine, curriculum, medical training, traditional, complementary and alternative medicine

\section{Background}

Traditional Thai medicine has historically been influenced by animistic traditions, Indian, Buddhist, and Chinese medical knowledge. ${ }^{1,2}$ "Thai traditional medicine means a medical procedure in relation to examination, diagnosis, therapy, treatment or prevention of disease or promotion and rehabilitation of human or animal health, obstetrics or Thai traditional massage."3 "The term [Complementary and Alternative Medicine] CAM often refers to a broad set of healthcare practices that are not part
Correspondence: Supa Pengpid ASEAN Institute for Health Development, Mahidol University, 25/25 Phutthamonthon 4 Rd, Salaya, Phutthamonthon, Nakon Pathom 73I70, Thailand

Tel +66 244I 0207

Email supaprom@yahoo.com 
of a country's own tradition and are not integrated into the dominant healthcare system." "Thai traditional medical profession means a profession relating to the practice of Thai traditional medicine and the practice of applied Thai traditional medicine." 5 The system of producing "Thai traditional medicine practitioners" can be either by "apprenticeship with an authorized licensed practitioner" or by studying at a certified academic institution. ${ }^{6}$ Based on the educational and the registration systems by the Thai Traditional Medical Council, the practice of Thai Traditional Medicine (TTM) can be divided into Thai traditional medicine and applied Thai traditional medicine. "While a licensed applied TTM practitioner can practice all areas of TTM mentioned above, a TTM practitioner has to obtain a license to practice in each of the three areas of traditional medicine, traditional pharmacy and Thai traditional midwifery." ${ }^{\prime 7}$ Over the past 20 years, there has been a large increase in the number of academic institutions for "Thai traditional medicine practitioners," now with 21 academic institutions offering a 4-year bachelor's degree in Thai traditional medicine. In 2009, the number of licensed practitioners were "17,001 TTM practitioners in Thai traditional medicine, 23,409 TTM practitioners in Thai traditional pharmacy, 5,735 TTM practitioners in Thai traditional midwifery, 332 TTM practitioners in Thai massage, and 660 Applied Thai traditional medicine practitioners."

Under the National Health Security system in Thailand, the types of TCAM services covered include "1) The treatment and diagnosis with Applied or Thai traditional medicine, 2) the treatment and rehabilitation with traditional herbal medicines or traditional recipes composing of medicinal plant materials, therapeutic massage for treatment and rehabilitation, and Traditional Chinese medicine (acupuncture)." "Applied TTM practitioners are allowed to use some simple modern medical equipment, eg, stethoscope, thermometer, sphygmomanometer. However, they can prescribe only traditional medicines." In 2014, 606 registered hospitals in Thailand had Thai traditional medicine, with 4,648,944 massage, hot compress, herbal stream visits, and 35,612 postpartum care visits. "It is estimated that among Thai people seeking care in public health facilities $10 \%$ receive Thai traditional medicine, which may include Thai traditional massage, herbal steam bath, traditional herbal medicines and acupuncture." "The integration of Thai traditional medicine into the national health care system includes the selection of 71 herbal medicinal products into the National List of Essential Drugs." 7,10

In various surveys, a high rate of TCAM utilization was found in the Thai population. ${ }^{11}$ Among a large sample of chronic disease patients across different regions in Thailand, the 12-month prevalence of consulting TCAM providers was $26.3 \%$ in Thailand; the most frequently consulted TCAM providers were the massage therapist $(15.1 \%)$, herbalist (9.6\%), acupuncturist (3.5\%), and spiritual healer $(0.3 \%) .{ }^{11}$ Furthermore, a high prevalence of TCAM use in patients visiting biomedical health facilities was found in Thailand, in particular for various chronic medical conditions, such as cancer, ${ }^{12,13}$ diabetes, ${ }^{11,14}$ asthma, chronic kidney disease, hypertension, ${ }^{15}$ and mental disorders. ${ }^{11}$

The use of TCAM is increasing, particularly among persons with chronic conditions, in many populations, which may have led to the incorporation of TCAM into the curricula of some medical schools in Western and Asian countries. ${ }^{16}$ In the United States, TCAM education as an elective course was offered in $64 \%$ of 117 medical schools in $1998^{17}$ and half of 130 medical schools $(50.8 \%)$ offered at least one TCAM course or clerkship in 2013. ${ }^{18}$ In European medical schools, $40 \%$ provide TCAM courses. ${ }^{20}$ In Japan, 16 medical schools $(20 \%)$ had introduced TCAM into their curriculum. ${ }^{21}$ In South Korea, $85.4 \%$ of 35 medical schools officially taught TCAM and $91.4 \%$ of 32 schools provided academic credit for TCAM courses. ${ }^{22}$

The topics most commonly taught in US medical schools were "acupuncture (76.7\%), herbs and botanicals (69.9\%), meditation and relaxation $(65.8 \%)$, spirituality/ faith/prayer (64.4\%), chiropractic (60.3\%), homeopathy $(57.5 \%)$, and nutrition and diets (50.7\%)." ${ }^{\prime \prime}$ In Korea, the commonly taught courses included "introduction to CAM or integrative medicine $(88.6 \%)$, traditional Korean medicine $(57.1 \%)$, homeopathy and naturopathy (31.4\%), and acupuncture (28.6\%)." ${ }^{22}$ At the Heidelberg Medical School in Germany, "classical naturopathy, acupuncture/ traditional Chinese medicine and neural therapy were integrated in the curriculum complementary and alternative medicine." ${ }^{23}$ In South Africa, most medical schools were teaching either African Traditional Medicine (TM) or CAM. ${ }^{16}$ A review of Thai traditional medicine training at university level found that the curriculum structure consists of following subject areas: general study, specific, basic medical science, Thai traditional medicine, and free elective. ${ }^{24}$

The aim of this study was to assess if undergraduate medical curricula included TCAM and, if so, to investigate what type of education was provided. In addition, where undergraduate degrees in TCAM were provided, the type of TCAM curricula was to be examined. Furthermore, the second goal of the study was to assess training in research, evidence-based health care, continuing education, and collaboration with biomedical peers offered at TCAM departments or faculties. 


\section{Methods}

\section{Sample TCAM curriculum in medical schools}

Participants included academic or curriculum deans and faculty at each of the medical schools in Thailand. A survey (by email, face-to-face, or telephonically) was conducted with these respective key informants using a questionnaire on TCAM curricula. A list of medical schools in Thailand was obtained from the Medical Council of Thailand. ${ }^{25}$

\section{Sample TCAM curriculum in TCAM departments or faculties}

Participants included academic or curriculum deans, heads of departments, and faculty at each of the TCAM faculties and departments in Thailand. A survey (by email, face-toface, or telephonically) was conducted with these respective key informants using a questionnaire on TCAM curricula and training. A list of approved Thai traditional medicine training institutions was obtained from the Thai Traditional Medical Council..$^{5}$

\section{Measure TCAM curriculum in medical schools}

The questionnaire developed based on literature review ${ }^{16,21,22,26}$ includes: presence of TCAM education, academic credit for TCAM, type of TCAM courses offered, description of course content, teaching and assessment methods for TCAM courses, amount of scheduled time, type of students, core competencies of attitude, knowledge, and skill of each course.

\section{Measure TCAM curriculum in TCAM departments/faculties}

The measure for TCAM departments/faculties was adapted from Toupin April et al, ${ }^{27}$ including characteristics of the TCAM training (number of students, instructors, curricula content), professional training of instructors, pedagogical approaches, satisfaction of the training offered, anticipated changes in the near future, curriculum improvement, and barriers and support to implement changes.$^{27}$ The study was conducted in 2017.

\section{Data analyses}

Data analyses were performed with IBM SPSS (version 24.0) (IBM Corporation, Armonk, NY, USA). The sample was described with descriptive statistics. In addition, content analysis was used for the open-ended questions.

\section{Ethics approval and consent to participate}

The study was conducted in accordance with the Declaration of Helsinki and was approved by the Faculty of Social Sciences and Humanities, Mahidol University, Thailand (MU-SSIRB 2016/149.1904). Written informed consent was obtained from each participant.

\section{Results}

\section{Undergraduate medical training}

Of the total of 21 medical schools (19 public and two private), 16 schools (76.2\%) responded to our questionnaire. Half of the medical schools (50\%) confirmed the presence of TCAM education in their medical school, of which most were a required and some an elective course. The course content of the reported TCAM courses are described in Table 1, covering mainly general introduction in TCAM, Thai traditional medicine, including herbal medicine, and therapeutic massage. TCAM modules or courses were offered during preclinical and clinical medical training, ranging from 3 to 24 hours (average 10 hours). TCAM courses were mainly delivered in the form of lectures, structured clinical experience, part of one or more preclinical problem-based learning cases, and small group discussion or presentation. Examples of a problem-based learning approach used are "Provide case study to students for analysis, formulate treatment plan based on their knowledge on modern and traditional medicine."

"We always use a problem learning approach with different scenarios of cases in the class. For example, we providing a specific information of patient and ask them to seek the additional information, discussion and making medical decision."

Table I Contents of TCAM course $(\mathrm{N}=8)$

\begin{tabular}{|l|l|l|}
\hline Topic & N & $\%$ \\
\hline Introduction to TCAM & 5 & 62.5 \\
$\begin{array}{l}\text { Traditional Thai medicine } \\
\text { Mind-body medicine (acupuncture, meditation, } \\
\text { yoga, hypnotherapy) }\end{array}$ & 6 & 75.0 \\
$\begin{array}{l}\text { Herbal medicine, natural products, others } \\
\text { (nutritional supplements or not specified) }\end{array}$ & 7 & 62.5 \\
$\begin{array}{l}\text { Manipulative and body-based practices (massage, } \\
\text { spinal manipulation, other) }\end{array}$ & 8 & 100.0 \\
$\begin{array}{l}\text { Homeopathy and naturopathy, energy field, art } \\
\text { therapy, aroma therapy } \\
\text { Equilibrium therapy } \\
\text { Other TCAM practices }\end{array}$ & 4 & 50.0 \\
\hline
\end{tabular}

Abbreviation: TCAM, traditional, complementary, and alternative medicine. 


\section{TCAM bachelor's degree training}

From 18 TCAM departments or faculties, 14 (77.8\%) responded to our questionnaire. In all 14 TCAM departments or faculties a bachelor's degree and in five institutions a master's degree in TCAM are offered. Undergraduate and postgraduate degrees include Thai Traditional Medicine (TTM), Applied Thai Traditional Medicine (ATTM), Chinese Traditional Medicine, and Oriental Medicine. For the production of "applied Thai traditional medicine practitioners," a four-year curriculum is required, including some basic life science, basic medical clinical science knowledge (anatomy, biochemistry, botany, pathology, pharmacology, pharmacognosy, and physiology) as prerequisite courses, and clinical training of Thai traditional medicine, pharmacy, midwifery, and Thai traditional therapeutic massage. Half of the surveyed 14 TCAM departments, schools, or faculties (50\%) had more than 100 students, and $50.0 \%$ had 21-50 lecturers (Table 2).

All lecturers had graduate training in a TCAM field, some MD and some were other biomedical practitioners (eg, RN, OT, PT). All respondents indicated that some lecturers or professors are involved in research activities. All programs offered a research course (average 84 hours, range 30-180 hours). Almost all indicated that their curriculum covers "scientific proofs about the efficacy and safety of treatments" (average 64 hours, range 15-200 hours).

More than half (9) indicated that their curriculum covers "how TCAM professionals should interact with biomedical peers (eg, nurse, rehabilitation professional, medical doctor)

Table 2 TCAM departments or schools or faculties offering undergraduate and/or postgraduate degrees $(\mathrm{N}=14)$

\begin{tabular}{|l|l|l|}
\hline $\begin{array}{l}\text { Department, school, or faculty of Thai or } \\
\text { oriental medicine }\end{array}$ & $\mathbf{N}$ & $\%$ \\
\hline Undergraduate degree & & \\
$\quad$ Applied Thai traditional medicine & 12 & 85.6 \\
Thai traditional medicine & 7 & 50.0 \\
Chinese traditional medicine & 2 & 14.3 \\
Oriental medicine & $\mathrm{I}$ & 7.1 \\
Postgraduate degree & 2 & 14.3 \\
Applied Thai traditional medicine & 2 & 14.3 \\
Thai traditional medicine & 1 & 7.1 \\
Chinese traditional medicine & 1 & 7.1 \\
Oriental medicine & & \\
Number of students & 3 & 21.4 \\
$<50$ & 4 & 28.6 \\
$50-100$ & 7 & 50.0 \\
$>100$ & 3 & \\
Number of lecturers & 4 & 21.4 \\
$<10$ & 7 & 50.0 \\
I0-20 & \\
$21-50$ &
\end{tabular}

Abbreviation: TCAM, traditional, complementary, and alternative medicine. in their practice" (average hours 60) or part of internship policy. All respondents mentioned that their institution's curriculum expected to change in the next 2-5 years, for example, "according to changing technology and society's needs, e.g.,, ageing society." "Symptomatology and diagnosis for applied Thai traditional medicine to get accepted and have had international standard practices." Recommendations from curriculum change included, "Add on conventional medicine content in the curriculum." "Scientific proof explanation should be increased." "Extend study period to 5-6 years." "Improve in research project." "Increase more hours for practicing."

Both the students and the administration of the departments or schools were generally perceived to be supportive to change the curriculum. However, barriers in the implementation of curriculum change were identified as follows, "Lecturers' old fashioned attitude may be difficult to change." "Authority and budget." "Criteria of curriculum improvement and linked with the framework of the Thai Traditional Medical Council." "Limitations in the number of instructors and advisors for students." "New knowledge, e.g., chiropractic and hammer massage." "Limitation in the number of patients per student, excluding the cases for Thai massage service."

Most participants indicated that they are satisfied or very satisfied with the TCAM training at their institution. This includes TCAM continuing education, research, scientific proofs, and interaction with medical peers (Table 3 ).

\section{Discussion}

The study investigated the training curricula of TCAM courses in medical schools and bachelor's degree courses in TCAM at universities and institutes in Thailand. Half of the medical schools had not incorporated TCAM courses in their curricula. This finding is similar to studies on TCAM curricula in medical schools in European medical schools $(40 \%),{ }^{20}$ in the USA $(50.8 \%),{ }^{18}$ higher than in Japan $(20 \%),{ }^{21}$ and lower than in South Korea (85.4\%) ${ }^{22}$ and South Africa (85.7\%). ${ }^{16}$ As many Thai patients do not only utilize biomedically trained doctors but also TCAM practitioners, all medical schools in Thailand should include a required module or course on TCAM into their curriculum. Medical schools in Thailand who already incorporated TCAM modules into their training were teaching topics similar in content to medical schools in other countries such as the USA and South Korea, ${ }^{19,22}$ including traditional medicine and to some extent complementary and alternative medicine.

On the other hand a large number of universities or institutes in Thailand trained TCAM practitioners at a degree level, mainly in applied Thai traditional medicine and a few on Chinese and oriental traditional medicine. Similarly, a number of universities in Malaysia offer bachelor's degree programs in 
Table 3 Satisfaction of TCAM training at your institution $(\mathrm{N}=14)$

\begin{tabular}{|c|c|c|c|c|}
\hline \multirow[t]{3}{*}{ TCAM variables } & \multicolumn{3}{|l|}{ Rating } & \multirow[t]{3}{*}{ Comments } \\
\hline & $\begin{array}{l}\text { Very or } \\
\text { dissatisfied or } \\
\text { neither satisfied } \\
\text { nor dissatisfied }\end{array}$ & Satisfied & $\begin{array}{l}\text { Very } \\
\text { satisfied }\end{array}$ & \\
\hline & $\%$ & $\%$ & $\%$ & \\
\hline Continuing education & 14.3 & 35.7 & 50.0 & "Students can continue their study in further degree right away" \\
\hline Research & 28.6 & 35.7 & 35.7 & $\begin{array}{l}\text { "Clinical research should be increased rather than only lab research" } \\
\text { "Experimental research has lots of limitations" }\end{array}$ \\
\hline Scientific proofs & 28.6 & 35.7 & 35.7 & $\begin{array}{l}\text { "Chinese traditional medicine is a science with scientific proof" } \\
\text { "It is a focal study issue of the curriculum that we wish to integrate Thai } \\
\text { Traditional Medicine into Medical Sciences" }\end{array}$ \\
\hline $\begin{array}{l}\text { Interaction with } \\
\text { biomedical peers }\end{array}$ & 21.4 & 42.9 & 35.7 & $\begin{array}{l}\text { "No problem" } \\
\text { "In Thailand, we have the national plan to encourage people who need } \\
\text { medical care to meet the TCAM professionals. We also provide TCAM } \\
\text { staff for every health care setting. Therefore, TCAM students have a great } \\
\text { opportunity to interact with other health professionals" }\end{array}$ \\
\hline
\end{tabular}

Abbreviation: TCAM, traditional, complementary, and alternative medicine.

various types of TCAM (traditional Chinese medicine, Malay medicine, complementary medicine, homeopathy, Ayurveda medicine, and chiropractic). ${ }^{28}$ Results from this study showed that all or almost all training institutions offered research methods and scientific proofs about the efficacy and safety of treatments, which is similar to regulated TCAM schools in Canada. ${ }^{27}$ Moreover, more than half of the training institutions indicated that their curriculum includes opportunities for collaboration with biomedical peers. Evidence-based health care training and interactions with biomedical peers are important to improve the recognition of TCAM. Most respondents were satisfied or very satisfied with the training offered at their institution, while some were not satisfied with the research part calling for more clinical research than lab research. Most respondents expected the curriculum to change to get applied Thai traditional medicine internationally accepted, by, eg, increasing evidence-based health care, increasing scientific proof, adding on conventional medicine, increasing research and practice hours, and extending the study period from 4 to 5 or 6 years.

In a review of the elements of applied Thai traditional medicine curricula at higher education institutions, Poopong ${ }^{24}$ found that "The contents of the curriculum emphasize subject matters which learners will be able to properly solve problems in professional practices; emphasize the study of basic medical science in order to diagnose and prescribe treatment properly with the application of Thai traditional medicine wisdom." And "The curriculum structure consists of following subject areas: general study, specific, basic medical science, Thai traditional medicine, and free elective; lecturers must have a degree in the field or have experiences in Thai traditional medicine which can be properly integrated in teaching." 24

\section{Study limitations}

Missing data in the two surveys hindered us from obtaining all relevant information from all medical schools and institutions with TCAM training. Considering the moderate response rate, results should be interpreted with caution. Moreover, a social desirability bias may have contributed to a more positive presentation of the TCAM curricula and related issues than they really are.

\section{Conclusion}

Regarding TCAM training modules of medical undergraduates, a number of medical schools had not integrated TCAM training, while another group had integrated them into their curriculum. It will be important to give all medical students exposure to TCAM practices in their curriculum, which may eventually improve patient care. Regarding the implementation of TCAM bachelor's degrees, the study confirmed the importance of the integration of research methodology, evidence-based health care, and interprofessional communication into the training of TCAM providers' training and practice. Most TCAM course coordinators were satisfied with their training, and some acknowledged problems, which should be addressed in further improving the curriculum.

\section{Author contributions}

Both authors contributed toward data analysis, drafting and critically revising the paper, gave final approval of the version to be published, and agreed to be accountable for all aspects of the work. 


\section{Disclosure}

The authors report no conflicts of interest in this work.

\section{References}

1. Salguero CP. Traditional Thai Medicine: Buddhism, Animism, Ayurveda. Chino Valley, AZ: Hohm Press; 2016.

2. Ratarasarn S. The Principles and Concepts of Thai Classical Medicine. Bangkok: Thai Khadi Research Institute, Thammasat University; 1986.

3. Pakorn Nilprapunt, Office of the Council of State. Protection and promotion of Knowledge on Thai Traditional Medical Act; B.E. 2542 (1999). Government Gazette, Vol. 116, Part 120a; November 1999. Unofficial translation; 2006. Available from: http:/www.krisdika.go.th/wps/wcm/ connect/920424804e34ac39bd8efdf7e6da8c7c/PROTECTION+AND + PROMOTION+OF+KNOWLEDGE+ON+THAI+TRADITIONAL + MEDICINE+ACT\%2C+B.E.+2542+\%281999\%29.pdf?MOD=AJP ERES\&CACHEID=920424804e34ac39bd8efdf7e6da8c7c. Accessed January 12, 2019.

4. World Health Organization. General Guidelines for Methodologies on Research and Evaluation of Traditional Medicine; WHO/EDM/ TRM/2000.1; 2000. Available from: https://apps.who.int/iris/bitstream/ handle/10665/66783/WHO_EDM_TRM_2000.1.pdf;jsessionid=E99B D12CE2A595092F11C6DB065B7781? sequence=1. Accessed January $12,2019$.

5. Thai Traditional Medical Council. [List of undergraduate institutions that the Council Accredits]; 2016. Previously available from: http:// www.thaimed.or.th/home/index.php/2016-08-23-09-10-33/513-alias70. Accessed March 2, 2018. Thai.

6. Globinmed. Thailand country report: background of medicinal system; 2012. Available from: http://globinmed.com/index.php?option=com content \&view=article \&id=103823:thailand-country-report2\&catid=257\&Itemid=317. Accessed April 4, 2018.

7. Chokevivat V, Chuthaputti A, Khumtrakul P. The use of traditional medicine in the Thai health care system, 2009. Available from: http:// www.searo.who.int/entity/medicines/topics/traditional_medicines_in_ the_kingdom_of_thailand.pdf. Accessed April 1, 2018.

8. National Health Security Office. NHSO Annual Report Fiscal Year 2014; 2015. Available from: https://www.nhso.go.th/eng/files/userfiles/ file/2018/001/NHSO\%20Annual\%20Report\%202014.pdf. Accessed March 1, 2018.

9. Department for Development of Thai Traditional and Alternative Medicine, Ministry of Public Health. Thailand: chronological development; 2011. Available from http://globinmed.com/index.php?option=com_con tent\&view=article \&id=105160:thailand\&catid=196: country-scenario. Accessed October 1, 2018

10. National Health Security Office. NHSO Annual Report Fiscal Year 2014; 2015. Available from: https://www.nhso.go.th/eng/files/userfiles/ file/2018/001/NHSO\%20Annual\%20Report\%202014.pdf. Accessed January 29, 2018.

11. Peltzer K, Pengpid S, Puckpinyo A, et al. The utilization of traditional, complementary and alternative medicine for non-communicable diseases and mental disorders in health care patients in Cambodia, Thailand and Vietnam. BMC Complement Altern Med. 2016;16(1):92.

Journal of Multidisciplinary Healthcare

Publish your work in this journal

The Journal of Multidisciplinary Healthcare is an international, peerreviewed open-access journal that aims to represent and publish research in healthcare areas delivered by practitioners of different disciplines. This includes studies and reviews conducted by multidisciplinary teams as well as research which evaluates the results or conduct of such teams or health Submit your manuscript here: https://www.dovepress.com/journal-of-multidisciplinary-healthcare-journa
12. Puataweepong P, Sutheechet N, Ratanamongkol P. A survey of complementary and alternative medicine use in cancer patients treated with radiotherapy in Thailand. Evid Based Complement Alternat Med. 2012;2012(4):1-6.

13. Supoken A, Chaisrisawatsuk T, Chumworathayi B. Proportion of gynecologic cancer patients using complementary and alternative medicine. Asian Pac J Cancer Prev. 2009;10(5):779-782.

14. Moolasarn S, Sripa S, Kuessirikiet V, et al. Usage of and cost of complementary/alternative medicine in diabetic patients. J Med Assoc Thai. 2005;88(11):25:1630-1637.

15. Tangkiatkumjai M, Boardman H, Praditpornsilpa K, Walker DM. Prevalence of herbal and dietary supplement usage in Thai outpatients with chronic kidney disease: a cross-sectional survey. BMC Complement Altern Med. 2013;13(1):153.

16. Chitindingu E, George G, Gow J. A review of the integration of traditional, complementary and alternative medicine into the curriculum of South African medical schools. BMC Med Educ. 2014;14(1):40.

17. Wetzel MS, Eisenberg DM, Kaptchuk TJ. Courses involving complementary and alternative medicine at US medical schools. JAMA. 1998;280(9):784-787.

18. Cowen V, Cyr V. Complementary and alternative medicine in US medical schools. Adv Med Educ Pract. 2015;6:113-117.

19. Brokaw JJ, Tunnicliff G, Raess BU, Saxon DW. The teaching of complementary and alternative medicine in U.S. medical schools: a survey of course directors. Acad Med. 2002;77(9):876-881.

20. Varga $\mathrm{O}$, Márton S, Molnár P. Status of complementary and alternative medicine in European medical schools. Complement Med Res. 2006;13(1):41-45.

21. Tsuruoka K, Tsuruoka Y, Kajii E. Complementary medicine education in Japanese medical schools: a survey. Complement Ther Med. 2001;9(1):28-33.

22. Kim DY, Park WB, Kang HC, et al. Complementary and alternative medicine in the undergraduate medical curriculum: a survey of Korean medical schools. J Altern Complement Med. 2012;18(9):870-874.

23. Joos S, Eicher C, Musselmann B, Kadmon M. Entwicklung, Implementierung und Evaluation eines «Curriculums Naturheilverfahren» an der Universität Heidelberg [Development and implementation of a 'curriculum complementary and alternative medicine' at the Heidelberg Medical School]. Forsch Komplementmed. 2008;15(5):251-260. German.

24. Poopong S. A study of the elements of Applied Thai Traditional Medicine Curriculum at higher education level. Master Thesis, M.Ed. (Educational Administration). Bangkok: Graduate School, Srinakharinwirot; 2006.

25. Thai Traditional Medical Council [homepage]. Available from: www. thaimed.or.th. Accessed May 2, 2017.

26. Ruedy J, Kaufman DM, MacLeod H. Alternative and complementary medicine in Canadian medical schools: a survey. CMAJ. 1999;160(6):816-817.

27. Toupin April K, Gaboury I. A survey of Canadian regulated complementary and alternative medicine schools about research, evidencebased health care and interprofessional training, as well as continuing education. BMC Complement Altern Med. 2013;13(1):374.

28. Kim YJ. The current studies of education for a traditional and complementary medicine in Malaysia. $J$ Evid Based Complementary Altern Med. 2017;22(4):531-537.

care processes in general. The journal covers a very wide range of areas and welcomes submissions from practitioners at all levels, from all over the world The manuscript management system is completely online and includes a very quick and fair peer-review system. Visit http://www.dovepress.com/ testimonials.php to read real quotes from published authors. 